\title{
Multi-channel IR sensor system for determination of oil degradation
}

\author{
T. Bley ${ }^{1}$, E. Pignanelli ${ }^{1}$, and A. Schütze ${ }^{1,2}$ \\ ${ }^{1}$ Centre for Mechatronics and Automation Technology (ZeMA), Saarbruecken, Germany \\ ${ }^{2}$ Lab for Measurement Technology, Department of Mechatronics, Saarland University, Saarbruecken, Germany
}

Correspondence to: E. Pignanelli (eliseo.pignanelli@mechatronikzentrum.de)

Received: 29 January 2014 - Revised: 14 May 2014 - Accepted: 19 May 2014 - Published: 12 June 2014

\begin{abstract}
A miniaturized infrared (IR) multi-channel sensor system was realized to determine chemical oil degradation, e.g., oxidation, increasing water content. Different artificially aged oil samples (synthetic motor oil, mineral hydraulic oil and ester-based hydraulic fluid) were prepared by oxidative degradation at elevated temperatures or addition of water, and characteristic degradation features in the IR spectrum were detected using FTIR spectroscopy. In addition, the absorption behavior of water contaminated synthetic motor oil was analyzed with increasing temperature. To determine the influence of different degradation effects on the measurement results the sensor system was characterized with the various oil samples. The system uses a reference channel to suppress the effect of decreasing transmission over the entire spectrum caused, e.g., by increasing soot content in the oil or contamination of the optical path.
\end{abstract}

\section{Introduction}

\subsection{Chemistry of oil deterioration}

To determine the type and degree of oil degradation different chemical processes have to be taken into consideration, e.g., oxidation, nitration and sulfation, but also increased water content. The speed of oxidation and the specific species in the oil generated by oxidative processes mainly depend on temperature. Oxidation itself is an autocatalytic process. In the temperature range between 30 and $120^{\circ} \mathrm{C}$ hydrocarbons react with metal catalysts, e.g., $\mathrm{Co}, \mathrm{Fe}, \mathrm{Cr}, \mathrm{Cu}, \mathrm{V}$ or $\mathrm{Mn}$, to alkyl radicals, depending on the strength of the C$\mathrm{H}$ bond. The alkyl radicals are converted via multiple reaction pathways to hydroperoxides and other alkyl radicals. Hydroperoxides are also generated by intramolecular propagation. These hydroperoxides break up into alkoxy and hydroxy radicals that take up hydrogen from the ambient. Secondary and tertiary alkoxy radicals react to aldehydes and ketones. The process terminates with a combination of radicals generating ketones and alcohols. At temperatures above $120^{\circ} \mathrm{C}$ the reaction pathway is generally similar but reaction speed is increased and the selectivity of the generated oxygen-containing compounds is reduced. Carboxylic acids and esters are formed by reactions with alcohol. At high temperatures the viscosity of the hydrocarbon increases due to polycondensation of oxygenated products. Unsaturated aldehydes or ketones are formed by aldol condensation. Alkoxy radicals can start the polymerization or polycondensation. The oxidation process is increased by metal soaps reducing the activation energy for the decomposition of alkyl hydroperoxides (Mortier et al., 2010).

The presence of nitrogen or sulfur oxides in the oil, e.g., introduced through the blow-by effect in combustion engines (Pawlak, 2003), can lead to oil degradation by nitration or sulfation. In addition, these gases in combination with water contamination can lead to formation of acids, further intensifying the polycondensation process. Ester-based fluids, e.g., native or phosphate esters, which are often used as hydraulic fluids, can break up into alcohols and acid components (hydrolysis) when exposed to increasing water content, especially at high mechanical load or elevated temperatures (Totten et al., 2003). Comprehensive online condition monitoring would therefore require a sensor capable of analyzing the degree of degradation and also the relevant degradation processes to allow an estimation of the remaining lifetime of the oil in the specific application. Furthermore, such a sensor 
system would also allow identification of degrading operating conditions, i.e., could help to remedy the cause of excessive oil degradation that would otherwise lead to shortened oil change intervals.

\subsection{State of the art}

Determination of the chemical degradation is highly desirable for oils and lubricants in order to optimize oil change intervals and to prevent undue wear in combustions engines, gear boxes or hydraulic machinery. One primary driver today is the increasing demand for offshore wind turbines in which the main gear is a critical component. In these systems, a complex set-up including filters and coolers is used for oil conditioning. Online determination of the oil status is especially beneficial here, as access is limited and maintenance is costly. Current methods for determination of oil degradation can be divided into two categories: sampling and online measurement.

Sampling requires oil samples to be taken at regular intervals followed by analysis in dedicated laboratories. Here, spectroscopic analysis methods, especially IR spectrometry, are used as well as titration, viscosimetry, etc. The obtained analysis results are interpreted automatically with threshold limits adapted to and determined by the oil type and the application. Ideally, the analysis provides a profound insight into the actual oil condition, allowing an analysis of the degradation process and also of the machinery itself, e.g., by analyzing the particle contamination of the oil where metal particles can provide additional information about the location of system damage on the basis of the detected material. However, sampling can also lead to false analysis results, e.g., when sampling is done under different operating conditions or at unsuitable sample points. For example, taking samples at different levels of the oil sump can lead to false, often increased, values for the particle concentration (Booser, 1994). In addition, sampling and subsequent laboratory analysis typically require several days to obtain the results, which could lead to increased machine degradation if oil degradation has already passed a critical value. Finally, for some applications such as offshore wind turbines, sampling is simply too expensive for regular operation.

To determine the true oil status in real time, online monitoring directly in the oil and close to critical components is highly desirable. Different sensors for online determination of various, mostly physical, oil properties, e.g., viscosity, dielectric constant but also water content, have been developed. However, these values indicate the chemical status of the oil only indirectly and a change in the sensor signal can also be caused by factors independent of the actual oil deterioration, e.g., a refill with slightly different oil with a different base component mixture or other additives. Therefore these values are difficult to interpret and to relate to the results of laboratory analysis. Multi-sensor systems combining several "indirect" sensors to obtain a more accurate assessment of the oil condition have been reported (Duchowsky and Mannebach, 2006), but their uptake in real applications is slow due to the ambiguity of the measurement results.

Optical measurement techniques are promising candidates for monitoring the oil quality, especially in the infrared (IR) spectral region, i.e., multi-channel NDIR (non-diffractive infrared) absorption or IR spectroscopy. The latter method is also used in laboratories, thus allowing better correlation of online data and lab results. Wideband IR characterization of the oil can provide a wealth of information concerning changes in the molecular structure of the oil, e.g., for determining the effects of oxidation, nitration and sulfation, the concentration of water, the status of additives in the oil (antioxidants and anti-wear compounds), as well as soot content (ASTM International, 2007). A direct adaptation of laboratory methods into an online monitoring system is, however, difficult due to the complexity of the typical laboratory setups and, in addition, varying ambient conditions have to be taken into account. Several groups are currently working on the development of miniaturized optical set-ups for online monitoring of the oil condition to allow correlation with existing laboratory methods.

Agoston et al. (2004, 2008) demonstrated an experimental set-up using an infrared source, $\mathrm{a} \mathrm{CaF}_{2}$ fluid measurement cell and one infrared detector for evaluating the oxidation of engine oils during deterioration processes. To select different relevant spectral regions, various custom-made band-pass filters $\left(1710,1970 \mathrm{~cm}^{-1}\right)$ were placed in the IR path. Kudlaty et al. (2003) showed a measurement set-up for lubricating oils based on attenuated total reflection (ATR) with a pyroelectric detector and a chopper wheel with two integrated narrow band-pass IR filters. Endisch and Koch (2007) demonstrated a set-up with a movable gradient filter, a reference filter, two infrared detectors and a ZnSe fluid measurement cell with variable thickness allowing a low resolution spectral analysis of the IR transmission spectrum for lubricating oils. Later, Wiesent et al. (2010) demonstrated a similar set-up with a detector array combined with the gradient filter to avoid the need for movable parts. Wiesent et al. (2011) also studied a set-up based on two microstructured tunable Fabry-Perot filters for analysis of different IR spectral regions applied to condition monitoring of gear oils in offshore wind turbines. While spectral information is of course very helpful for data acquisition and comprehensive analysis, these systems are rather costly, thus preventing their widespread use. At the same time, the microcomponents used in these set-ups can only be manufactured at acceptable prices, if large volumes can be reached. Thus, these solutions while achieving promising results have not yet entered the market on a larger scale. Sumit et al. (2010) presented a system with an infrared source, a fluid cell consisting of two sapphire windows and a quadruple infrared detector equipped with different filter windows for analysis of phosphate ester hydraulic fluids, especially for aerospace applications. 
In addition to approaches based on IR measurements for determining the oil quality, Schneidhofer and Dörr (2009) presented an oil monitoring system based on chemical corrosion sensors allowing an analysis of the acidic content of the oil. Finally, Wang (2001) used a set-up with platinum electrodes to determine oil changes in a car by measuring the consumption or transformation of additives. However, longterm stability and resolution are also a recurring concern for chemical sensor systems, especially in harsh environments such as gear boxes.

Taking into account the results obtained for the different methods, which clearly show the most promising results for multichannel NDIR measurements offering a good trade-off between information quality, stability and cost, an integrated sensor system based on MEMS components was developed, similar to the system demonstrated by Sumit et al. (2010). The modular system also uses a, in our case, commercially available microstructured infrared source and quadruple thermopile detector. To allow realization of a compact, low-cost sensor system with the focus on industrial applications, a fluidic cell based on silicon and realized using established microtechnologies is used. Compared to Sumit et al. (2010), the Si-based cell allows measurements over a wider spectral range $\left(8000-1250 \mathrm{~cm}^{-1}\right.$ corresponding to wavelengths of 1.25 to $8 \mu \mathrm{m}$ ), providing more information about the measured oil, because further relevant spectral changes can be determined. Si wafers with a thickness of $2 \mathrm{~mm}$ are used as base material for the fluid cell, allowing the realization of a sensor system able to monitor the mid-infrared spectrum up to a wavelength of $9 \mu \mathrm{m}$ (Czochralski silicon) with a small and well-defined IR absorption path length of $200 \mu \mathrm{m}$. The channel is realized using pre-structured LTCC (low-temperature co-fired ceramic) spacers deposited on top of the $\mathrm{Si}$ wafer. Cells are realized using a batch process and mounted in a housing after dicing. The fluidic cell can be operated at pressures up to 100 bar (Bley et al., 2012b) due to the high bond strength between $\mathrm{Si}$ and the LTCC further optimized by nanostructuring of both materials as demonstrated by Günschmann et al. (2013). In addition, silicon oxide formed on the Si wafer surface is chemically inert, thus offering sufficient long-term stability against oil components and the reactive products of oil deterioration and contamination.

Some results obtained with the novel sensor system were presented previously (Bley and Schütze, 2011; Bley et al., 2012a, b, c). This paper is based on preliminary results presented in Bley et al. (2012a) and has been extended with measurements concerning the influence of temperature changes on the spectral transmission and especially reference measurements of acid number and viscosity. These were correlated with results of the measurement system for different oil types.

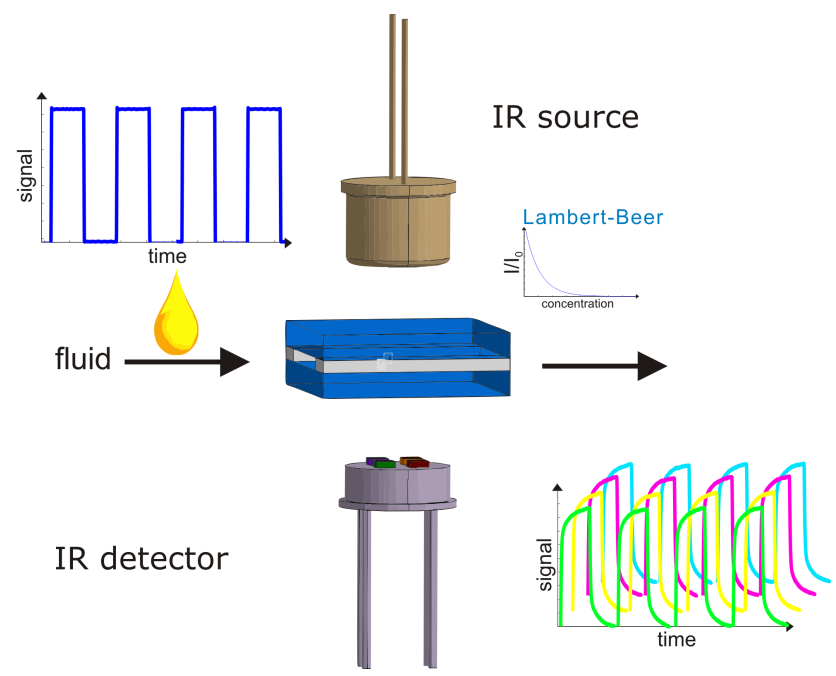

Figure 1. Schematic of the sensor system (Bley et al., 2012c).

\section{Experimental}

\subsection{Sensor system}

Based on spectral characterization of various oils and lubricants a miniaturized sensor system with an IR transparent silicon cell was developed for optical analysis of technical fluids in general and particularly for lubricating or hydraulic oils (Bley and Schütze, 2011). A schematic of the sensor system is shown in Fig. 1.

A commercial infrared source (Intex Inc., 2013) with a maximum permissible heater power of $980 \mathrm{~mW}$, broad IR emission spectrum similar to a black body and a spectral time constant of $30 \mathrm{~ms}$ (heating) and $5 \mathrm{~ms}$ (cooling) is excited with a square wave signal at a frequency of $0.2 \mathrm{~Hz}$. The small excitation frequency is used to ensure maximum signal intensity, i.e., allowing the IR source to reach its maximum temperature and also the thermopile detectors to reach steady state and to record signal amplitude and offset with a good signalto-noise ratio. The electrical power used for the IR source in the on phase is approximately $715 \mathrm{~mW}$, which achieves an increased lifetime (10 times) of the infrared source compared to operation at maximum power. The radiation of the IR source passes through the silicon cell in which a fluid channel with a height of $200 \mu \mathrm{m}$ is defined using an LTCC spacer (Günschmann et al., 2012). The broadband spectrum of the IR source is attenuated at specific wavelengths depending on the specific spectral extinction $\varepsilon(\lambda)$ and concentration $c$ of molecular species in the fluid as well as the film thickness $d$ according to the Lambert-Beer law (Burns and Ciurczak, 2008):

$I(\lambda)=I_{0} \cdot e^{-\varepsilon(\lambda) \cdot c \cdot d}$.

A modified commercial quadruple thermopile detector (Micro-Hybrid Electronic GmbH, 2013) with a thermal time 
constant of approximately $100 \mathrm{~ms}$ was used to detect the transmitted radiation. Each detector has a specific bandpass filter where the center wavelengths of three filters are matched to characteristic absorption features of the fluid, while the fourth is used as a reference channel. For reference a spectral region without characteristic absorption by the oil is selected to suppress the influence of broadband attenuation, e.g., soot contamination of the oil or degradation of the IR source or the optics.

In this paper oils based on hydrocarbons and on native esters are analyzed. During aging, both hydrocarbon oils and ester-based hydraulic fluids generate reaction products containing a carbonyl group. Thus, measuring the IR attenuation in the carbonyl-specific wavelength region in principle allows determination of the current oxidation condition of the oil. Ester-based hydraulic fluids, however, already contain carbonyl groups in their regular molecular structure, resulting in an almost complete absorption of the IR radiation in this region. Therefore, other specific regions in the IR spectrum, e.g., influenced by the hydroxyl group $(\mathrm{OH})$, are required for determination of the oxidative degradation for ester-based hydraulic fluids. Consequently, the sensor set-up uses different, relevant regions of the IR absorption spectrum adapted to the general oil type (hydrocarbon oil or ester-based hydraulic fluid). Filter combination A is used for hydrocarbon-based oils, while filter combination B is used for ester-based hydraulic fluids; the filter parameters are listed in Tables 1 and 2, respectively. For each oil type the IR reference channel of the detector (AR, BR) is selected so that it is close to a one of the three measurement channels in order to minimize measurement errors resulting from, e.g., high soot content that can lead to a tilt of the IR spectrum (Mortier et al., 2010). Note that the filter selection can also be adapted to the expected dominating degradation processes, which are very different for combustion engines, gear boxes or hydraulic systems.

The raw detector signals, which are typically in the range of less than $5 \mathrm{mV}$, are amplified and electronically filtered with an active low-pass filter $\left(72 \mathrm{~Hz}, 20 \mathrm{~dB}\right.$ decade $\left.^{-1}\right)$. The electronic amplification stage has an overall gain of 341 . The amplified signals are recorded with a sampling rate of $500 \mathrm{~Hz}$ using a 16 bit analog-to-digital converter with a realtime data acquisition system (CompactRIO System 9074, National Instruments) with a LabVIEW graphical user interface (GUI). The raw sensor signals of all four thermopile detectors are recorded over 12 consecutive on/off pulses of the IR source, i.e., over a total period of $60 \mathrm{~s}$, and then evaluated in a post process in MATLAB using a DFT algorithm. The first harmonic DFT component of the detector signals, denoted below as DFT amplitude, is evaluated to improve the signal-to-noise ratio.

For evaluation of the sensor system with different oil samples a simple test set-up based on a membrane pump (KNF NF1.11) was realized. Each sample was pumped through the sensor system at a constant flow rate between 50 and

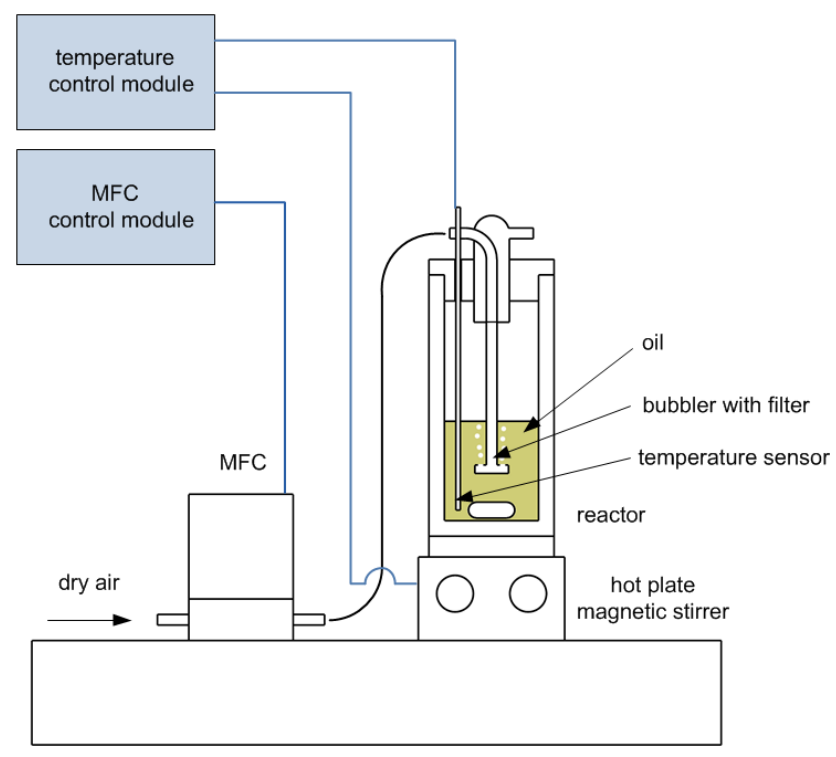

Figure 2. Experimental set-up for defined oil degradation by oxidation.

$100 \mathrm{~mL} \mathrm{~min}^{-1}$. After analysis of each sample the sensor system was cleaned with n-heptane and dry air to prevent carryover from the different oil samples. The system also allowed testing under various pressure regimes and temperatures (Bley et al., 2012b).

\subsection{Artificial oil degradation}

To prepare different oil samples with well-defined and reproducible oxidative degradation a reactor set-up was realized as shown in Fig. 2. An oil sample $(1500 \mathrm{~mL})$ was placed in an aluminum reactor vessel that was heated to $170^{\circ} \mathrm{C}$ for hydrocarbon oils and to $130^{\circ} \mathrm{C}$ for ester-based hydraulic fluids using a hot plate to simulate extended operation of the oil in contact with ambient air. The temperature in the reactor was controlled with a temperature sensor placed directly in the oil to control the hot plate power. A mass flow controller (MFC) provided a constant flow of $50 \mathrm{~mL}$ dry air through the oil in the reactor. The MFC was connected to a bubbler with glass filter, which was dipped into the oil, generating finely distributed bubbles. The oil was continuously stirred using a magnetic stirrer. To analyze the degradation at different stages samples of $100 \mathrm{~mL}$ each were taken after predefined intervals; typically, four samples were taken over a period of several days. A volume of $100 \mathrm{~mL}$ per sample was chosen to minimize the effect of sampling on the degradation process on the one hand and to obtain sufficient material for analysis and testing on the other.

Samples with additional water contamination of $0.1,0.2$ and 0.4 weight percent (wt.\%), respectively, were prepared by adding pure water (ASTM type II, cf. ASTM International, 2011a) to new and artificially aged oil samples. The samples were stirred with a magnetic stirrer at room 
Table 1. Filter parameters of the band-pass filters for analysis of hydrocarbon-based oils, i.e., mineral and synthetic oils (filter combination A, hydrocarbon configuration).

\begin{tabular}{lllll}
\hline & Filter A1 & Filter A2 & Filter A3 & Filter AR \\
\hline Center wavelength $\left[\mathrm{cm}^{-1}\right]$ & 1722 & 3333 & 3532 & 2513 \\
FWHM $\left[\mathrm{cm}^{-1}\right]$ & 151 & 52 & 52 & 54 \\
Absorption band (indicator) & Carbonyl group (oxidation) & Hydroxyl group (water) & Hydroxyl group (water) & Reference (soot, etc.)
\end{tabular}

Table 2. Filter parameters of the band-pass filters for analysis of ester-based hydraulic fluids (filter combination B, ester configuration).

\begin{tabular}{lllll}
\hline & Filter B1 & Filter B2 & Filter B3 & Filter BR \\
\hline Center wavelength $\left[\mathrm{cm}^{-1}\right]$ & 3333 & 3514 & 3634 & 3910 \\
FWHM $\left[\mathrm{cm}^{-1}\right]$ & 52 & 52 & 52 & 71 \\
Absorption band (indicator) & Hydroxyl group (oxidation) & Hydroxyl group (oxidation) & Hydroxyl group (water) & Reference (soot, etc.) \\
\hline
\end{tabular}

temperature for several minutes after adding the water. Analysis was performed immediately afterwards to prevent segregation of oil and water mixture.

To measure the spectral influence of added water in combination with increasing temperature, oil samples with added water were filled into a closed fluid measurement cell (Omni Cell System, Specac). The samples were heated in the cell on a hotplate, controlled with a PT1000 sensor connected to the cell and then measured with the FTIR. Based on the negligible surface of oil and air during filling and the closed measurement cell evaporation of the water can be neglected.

For the determination of relevant spectral degradation features different oils were used:

- Hydrocarbon-based oils

- Synthetic motor oil (Pegasus 1, Mobil)

- Mineral hydraulic oil (Tellus Oil 46, Shell)

- Ester-based hydraulic fluid

$$
\text { - Native ester (HETG 37, Meguin) }
$$

The synthetic motor oil and the mineral hydraulic oil are both hydrocarbon based and also contain various additives. The native ester fluid, on the other hand, is based on a molecular structure obtained by esterification of triglycerides, also with various additives. The two different molecular bases of the fluids cause different IR spectra with different regions of interest as shown in Sect. 3.1 below.

In addition to the artificially aged samples of the synthetic motor oil samples of the identical oil were taken from the gas engine of a combined heating and power unit (CHP) after 1025 and 1840 working hours, respectively. A standard laboratory analysis of these samples showed the oil to be marginal after $1025 \mathrm{~h}$ and strongly advised an immediate oil change after 1840 working hours. It was expected that these samples aged under actual operating conditions would show degradation effects in addition to oxidation due to, e.g., blowby gases containing sulfur and nitrogen oxide and also water.

\subsection{Reference IR spectra, acid number and viscosity}

Each oil sample was analyzed using a high resolution FTIR spectrometer (Vertex 80V, Bruker Corporation, USA) to obtain reference spectra before testing with the multi-channel IR sensor system. In the spectrometer a fluid cell with $200 \mu \mathrm{m}$ film thickness was used (Omni Cell with $\mathrm{CaF}_{2}$ windows). The fluid cell was placed in the sample chamber of the FTIR spectrometer and spectra were recorded from 1000 to $4000 \mathrm{~cm}^{-1}$ at a resolution of $0.5 \mathrm{~cm}^{-1}$. To analyze the influence of temperature on the IR spectra the oil samples were heated in the FTIR spectrometer using a hot plate and a fluid cell with integrated PT1000 temperature sensor.

In addition to the reference IR spectra the oil samples were further characterized by determining the acid number (AN) and the kinematic viscosity $(\eta)$. The AN was determined by titration according to ASTM D974 guidelines (ASTM International, 2011b) using a Schott Titroline 6000. The kinematic viscosity was determined at 40 and $80^{\circ} \mathrm{C}$ using an Ubbelohde viscometer.

\section{Results}

\subsection{IR spectra}

\subsubsection{Synthetic motor oil}

The spectrum of the synthetic motor oil shows multiple characteristic effects indicating the oil degradation under normal operating conditions as shown in Fig. 3. The oil aged over 1840 working hours shows a slight increase in broadband absorption caused by an increase in soot particles in the oil. Increased absorption is observed in the spectral region from 3100 to $3500 \mathrm{~cm}^{-1}$. OH groups as found, e.g., in alcohols, and water and also amines can lead to an increased absorption in this spectral region. In oil samples, the water absorption peak is usually shifted toward higher wave numbers (Sumit et al., 2010); therefore we assume that the increased 


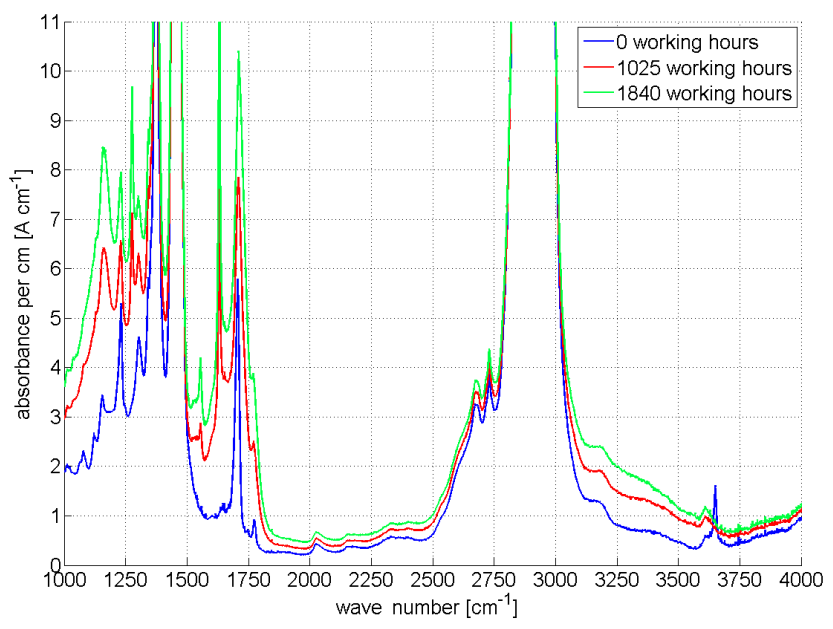

Figure 3. IR spectra of synthetic motor oil from a gas engine (combined heating and power unit) at different stages of aging under normal operating conditions.

absorption is caused by an increased concentration of alcohols due to oxidation.

The fresh oil shows a characteristic peak at $1700 \mathrm{~cm}^{-1}$, which is probably due to an additive with a $\mathrm{C}=\mathrm{O}$ double bond, e.g., an ester. With increased aging a strong increase in this peak is observed caused by an increasing concentration of oxidized molecules with $\mathrm{C}=\mathrm{O}$ double bonds, e.g., aldehydes, ketones and carboxylic acids. At $1630 \mathrm{~cm}^{-1}$ a sharp absorption feature increases dramatically, which can be attributed to nitration of the oil due to nitrogen oxide carry-over caused by the blow-by effect in combustion engines (Pawlak, 2003).

The observed signal increase at $1150 \mathrm{~cm}^{-1}$ can be attributed to sulfation products while peaks at $1277 \mathrm{~cm}^{-1}$ and $1555 \mathrm{~cm}^{-1}$ suggest further reactions to nitrogen or oxygen containing compounds. At $3650 \mathrm{~cm}^{-1}$ the spectrum of the fresh oil shows a feature that is no longer evident in the aged samples. This absorption peak is probably due to a phenolic antioxidant additive (Pawlak, 2003; Pretsch et al., 2009), which is consumed under operating conditions and already used up after 1025 working hours.

It can be concluded that the spectrum of the synthetic motor oil shows multiple characteristic effects during aging. For an exact calibration of the sensor system the different degradation features in the IR absorption spectrum have to be analyzed separately to allow independent quantitative analysis of the various causes using the multi-channel system.

The spectrum of the synthetic motor oil artificially aged at $170^{\circ} \mathrm{C}$ shows a characteristic increase in the $\mathrm{C}=\mathrm{O}$ double bond feature at $1700 \mathrm{~cm}^{-1}$ as shown in Fig. 4. After 9 days of artificial aging the peak height of this oxidation feature is comparable to that of the sample aged for 1025 working hours under operating conditions. In addition, a continuous increase in the $\mathrm{OH}$ feature at $3100-3500 \mathrm{~cm}^{-1}$ is observed,

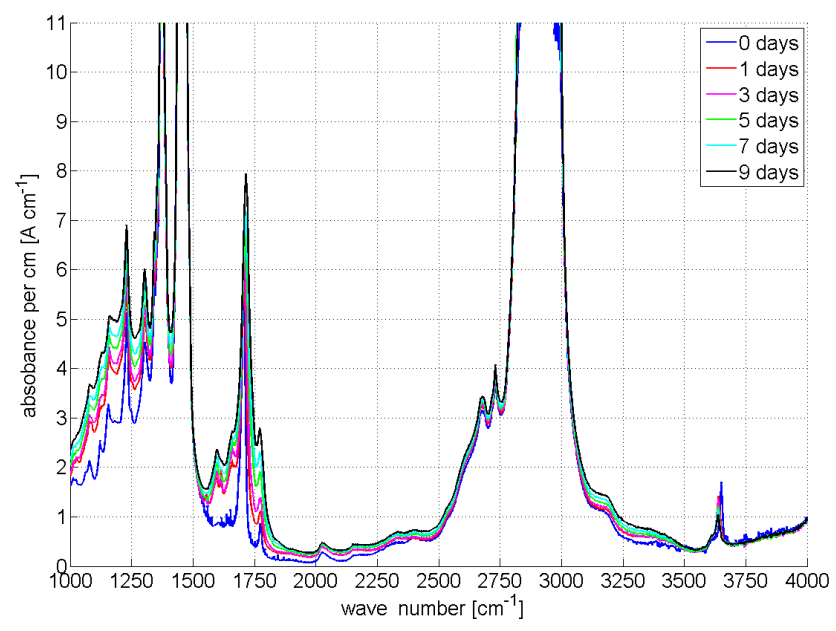

Figure 4. IR spectra of synthetic motor oil $(1500 \mathrm{~mL})$ artificially aged at $170{ }^{\circ} \mathrm{C}$ with $50 \mathrm{~cm}^{3} \mathrm{~min}^{-1}$ air flow over 9 days.

which is similar in shape but somewhat smaller compared to the $\mathrm{OH}$ feature of the synthetic motor oil under operating conditions. This could indicate a higher water content of the samples from the CHP compared to the artificial aging in which no water could accumulate in the oil due to the high temperature during aging. However, while additional contamination of the synthetic motor oil with water also leads to increased absorption in this spectral region, as shown in Fig. 5, the resulting peak is shifted to larger wave numbers compared with the spectra shown in Figs. 3 and 4, respectively. The maximum absorption increase is observed at approximately $3400 \mathrm{~cm}^{-1}$ for increased water content compared to a maximum in the range of $3200 \mathrm{~cm}^{-1}$ observed both for aging under operating conditions as well as for artificial oxidation. This indicates that the larger $\mathrm{OH}$ absorption feature in the synthetic motor oil aged under operating conditions is caused by oxidation or other products caused by the reaction of oil and exhaust gases. Thus, the artificial aging employed here does not perfectly reflect the oxidation process under operating conditions.

The synthetic motor oil also shows that the concentration of different additives, e.g., with a carbonyl group (ester) or phenolic antioxidants, can be determined at a film thickness of $200 \mu \mathrm{m}$ at wavelengths of 1700 and $3650 \mathrm{~cm}^{-1}$, respectively. Very high additive concentrations could possibly attenuate the IR signal completely; thus, the system would have to be adapted by choosing an appropriate absorption path length, i.e., oil film thickness.

\subsubsection{Mineral hydraulic oil}

The spectra of the mineral hydraulic oil also artificially aged at $170^{\circ} \mathrm{C}$ show a strong increase in the sharp $\mathrm{C}=\mathrm{O}$ double bond feature at $1700 \mathrm{~cm}^{-1}$ and a smaller increase in the broad $\mathrm{OH}$ feature at $3100-3500 \mathrm{~cm}^{-1}$ (Fig. 6) comparable 


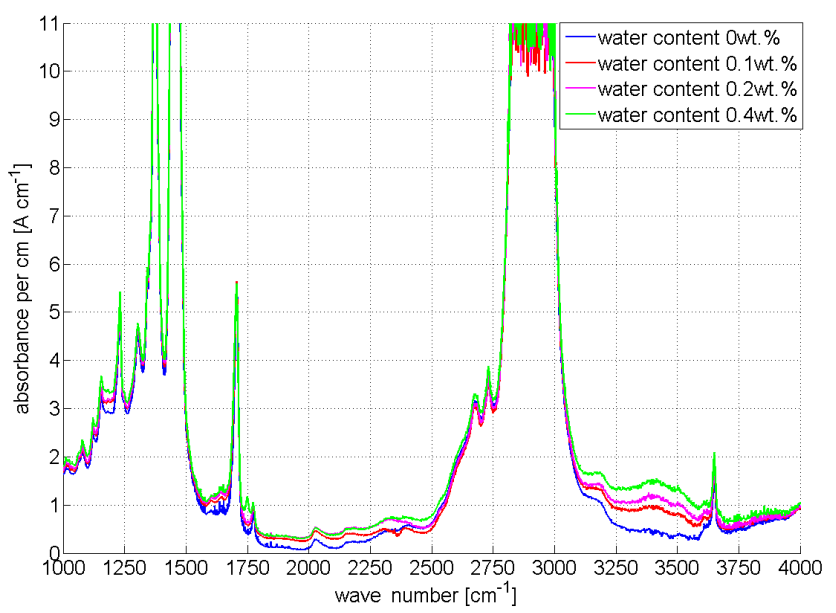

Figure 5. IR spectra of synthetic motor oil with added water (ASTM type II, 0, 0.1, 0.2 and $0.4 \mathrm{wt} . \%$, respectively).

to the results observed for the artificially aged synthetic oil. This similarity is due to the similar molecular base structure that is predominantly based on hydrocarbons for both oils. The main difference is the absence of the $\mathrm{C}=\mathrm{O}$ double bond feature for the fresh mineral hydraulic oil because it does not contain the ester additive as the synthetic motor oil. Also, the increase in the two relevant peaks seems slightly slower for the hydraulic oil, which could indicate a better oxidation stability. Comparison of the spectral features, however, indicates that the same spectral regions are relevant; thus, a multi-channel system with the same filter configuration could be used for both oils.

\subsubsection{Ester-based hydraulic fluid}

The spectra for native ester artificially aged at $130{ }^{\circ} \mathrm{C}$ show different oxidation features compared to the synthetic and mineral oils shown above. At $1700 \mathrm{~cm}^{-1}$ the $\mathrm{C}=\mathrm{O}$ double bond feature due to an oxidation via hydroperoxides (Honary and Richter, 2011) overlaps with the $\mathrm{C}=\mathrm{O}$ double bond of the ester itself (Fig. 7) (Totten et al., 2003). Even for a film thickness of only $200 \mu \mathrm{m}$ the IR radiation is completely absorbed in the area of $1700 \mathrm{~cm}^{-1}$ and, thus, cannot be evaluated for the determination of the oxidation status. Increasing absorption caused by increasing aging is observed in a broad spectral region around $3500 \mathrm{~cm}^{-1}$ and, to a lesser extent, around 2500 and around $1600 \mathrm{~cm}^{-1}$ on the shoulder of the saturated $\mathrm{C}=\mathrm{O}$ double bond feature. The main feature around $3500 \mathrm{~cm}^{-1}$ is most suitable to obtain sufficient sensitivity for determination of the oil degradation by oxidation. However, comparing this result with the water contamination of the synthetic motor oil (cf. Fig. 4), an increasing water content would probably interfere with the oxidation in this spectral region (ASTM International, 2007) and thus, multiple channels would be required to be allow separate determination of oxidation and water contamination.

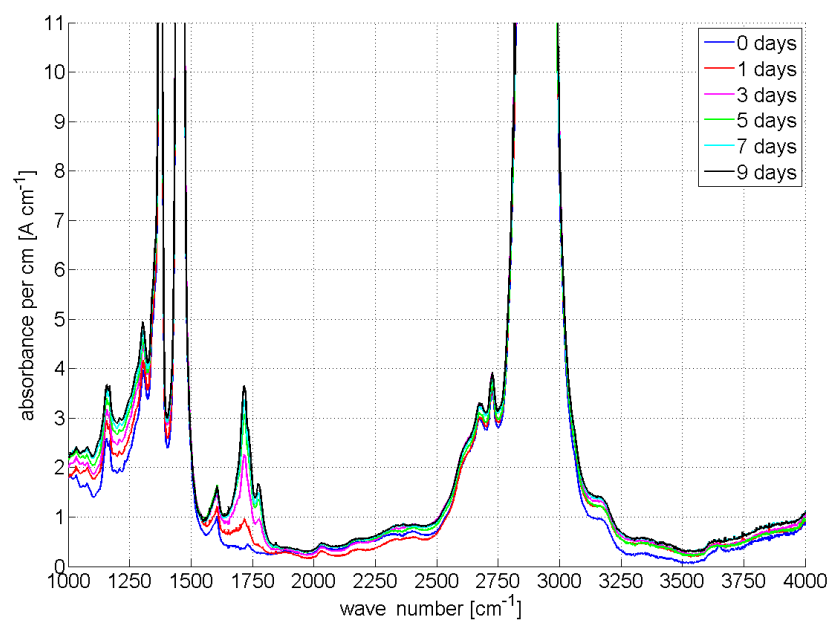

Figure 6. IR spectra of mineral hydraulic oil $(1500 \mathrm{~mL})$ artificially aged at $170^{\circ} \mathrm{C}$ with $50 \mathrm{~cm}^{3} \mathrm{~min}^{-1}$ air flow over 9 days.

Table 3. Acid number (AN) and kinematic viscosity $\eta$ for synthetic motor oil (Mobil Pegasus 1); actual samples taken from a gas engine in a combined heating and power unit.

\begin{tabular}{lrrrr}
\hline & $0 \mathrm{~h}$ & $1025 \mathrm{~h}$ & $1840 \mathrm{~h}$ & Limit \\
\hline $\mathrm{AN}\left[\mathrm{mg} \mathrm{KOH} \mathrm{g}^{-1}\right]$ & 0.7 & 8.22 & 10.1 & $>5^{*}$ \\
$\eta\left[\mathrm{mm}^{2} \mathrm{~s}^{-1}\right]$ & 92 & 123 & 163 & $\pm 35 \%$ \\
\hline
\end{tabular}

* Recommended limit values for mineral hydraulic fluids.

\subsection{Acid number and viscosity}

To complement the spectral features, additional measurements were performed to evaluate the quality and the degree of degradation of the different oils. The obtained results are compared with limit values proposed by Möller and Nassar (2002) for turbine and mineral hydraulic oils and Booser (1994) for engine oils (cf. Tables 3-6). The limit values for kinematic viscosity and AN given in the tables show the maximum acceptable deviation compared to fresh oil. For some specific applications limit values are not defined; these are instead compared to values of other applications and marked in the tables.

For synthetic motor oil, a similar height of the $\mathrm{C}=\mathrm{O}$ oxidation peak is reached after artificial aging for 9 days at $170^{\circ} \mathrm{C}$ as for 1025 working hours under normal operating conditions (cf. Figs. 3 and 4). In comparison, the AN and viscosity of the sample aged under operating conditions show higher values compared to the artificial aging, see Tables 3 and 4 . The higher AN results can be attributed to the increase in nitric acids in the oil, which also enhances polycondensation in the oil and increases the viscosity. However, the limit value taken from the literature would indicate that the oil is close to the limit after 1025 working hours, similar to the laboratory analysis, which indicates aging but still acceptable performance of the oil. The mineral hydraulic oil already 
Table 4. Acid number (AN) and kinematic viscosity $\eta$ for synthetic motor oil (Mobil 1 Pegasus); artificially aged samples, cf. Fig. 4.

\begin{tabular}{lrrrrr}
\hline & 0 days & 3 days & 7 days & 9 days & Limit \\
\hline $\mathrm{AN}\left[\mathrm{mg} \mathrm{KOH} \mathrm{g}^{-1}\right]$ & 1.15 & 3.4 & 7 & 7.7 & $\Delta>+2,5$ \\
$\eta\left[\mathrm{mm}^{2} \mathrm{~s}^{-1}\right]$ & 90 & 94 & 101 & 110 & $\pm 35 \%$ \\
\hline
\end{tabular}

* Limit value suggested by OelCheck (2013).

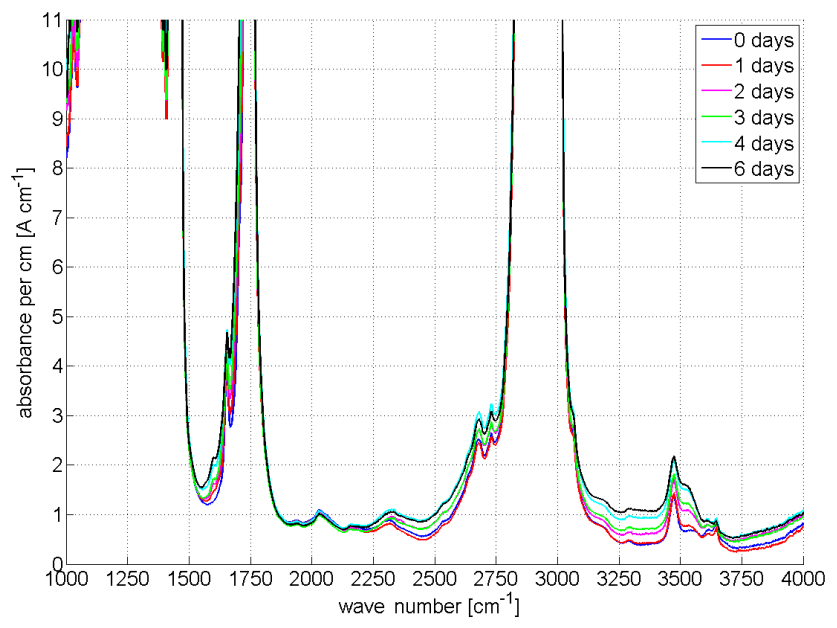

Figure 7. IR spectrum of ester-based hydraulic fluid $(1500 \mathrm{~mL})$ artificially aged at $130{ }^{\circ} \mathrm{C}$ with $50 \mathrm{~cm}^{3} \mathrm{~min}^{-1}$ air flow over 6 days.

reaches the recommended threshold limit of the kinematic viscosity after only 3 days of artificial aging, see Table 5 . The ester-based hydraulic fluid, finally, already exceeds the threshold limit of the viscosity after less than 2 days due to its lower resistance against oxidation (Bartz, 1993).

Figure 8 shows the IR absorption signal integrated over the characteristic oxidation region in the spectrum plotted vs. the measured AN of the three oil types for all artificially aged samples. All three show nearly linear correlation between IR absorption and AN. Note that due to the much smaller increase in the oxidation feature for the native ester the recorded slope is smaller than the slope of the synthetic motor oil and the mineral hydraulic oil. The different IR absorption values of the fresh samples for synthetic motor oil and mineral hydraulic oil are caused by the additive in the synthetic motor oil, which interferes with the measurement of the oxidation signal. It can be concluded that IR absorption measurement in a suitable spectral range allows an estimation of the AN, at least for thermal deterioration; however, the oil base type as well as the additives have to be taken into account, thus requiring individual calibration. When considering motor oils, on the other hand, estimation of the AN is more difficult due to additional acidic components generated by the combustion process and also blow-by gases. Therefore additional spectral ranges have to be taken into account.
Table 5. Acid number (AN) and kinematic viscosity $\eta$ for mineral hydraulic oil (Shell Tellus); artificially aged samples.

\begin{tabular}{lrrrr}
\hline & 0 days & 3 days & 7 days & Limit \\
\hline $\mathrm{AN}\left[\mathrm{mg} \mathrm{KOH} \mathrm{g}^{-1}\right]$ & 0.54 & 2.01 & 2.31 & $>5$ \\
$\eta\left[\mathrm{mm}^{2} \mathrm{~s}^{-1}\right]$ & 44 & 49 & 56 & $\pm 10 \%$ \\
\hline
\end{tabular}

Table 6. Acid number (AN) and kinematic viscosity $\eta$ for esterbased hydraulic fluid (Meguin HETG 37); artificially aged samples.

\begin{tabular}{lrrrrr}
\hline & 0 days & 2 days & 4 days & 6 days & Limit \\
\hline $\mathrm{AN}\left[\mathrm{mg} \mathrm{KOH} \mathrm{g}^{-1}\right]$ & 0.67 & 3.0 & 4.95 & 6.7 & $>5^{*}$ \\
$\eta\left[\mathrm{mm}^{2} \mathrm{~s}^{-1}\right]$ & 35.0 & 42.3 & 50.0 & 59.5 & $\pm 10 \%$ \\
\hline *
\end{tabular}

${ }^{*}$ Recommended limit values for mineral hydraulic fluids.

\subsection{Multi-channel IR sensor system}

The recorded IR spectra of the different oils have indicated specific spectral regions for determination of oxidation and water contamination for the hydrocarbon-based oils. On the other hand, IR analysis of the ester-based hydraulic fluid has shown an overlap of the spectral regions, indicating oxidation and water contamination. The same oil samples, fresh, artificially aged and, in the case of the synthetic motor oil, aged under operating conditions, were analyzed with the sensor system to evaluate the suitability of the system for determination of the two relevant conditions. For the two hydrocarbonbased oils the detector configuration A, Table 1, was used and for the native ester detector configuration $\mathrm{B}$. The signal intensity is normalized, i.e., the values for fresh oils are set to one.

The measurement results for the artificially aged samples of the synthetic motor oil (Fig. 9) show a continuous decrease in the reference channel AR due to an increase in soot particles in the oil. Therefore, the three measurement channels were weighted by dividing the normalized values through the reference channel signal to compensate for this effect. After normalization, a strong decrease in channel A1 corresponding to the $\mathrm{C}=\mathrm{O}$ feature is observed for increasing aging as expected from the reference spectra (cf. Fig. 4). In addition, a slight decrease in channel $\mathrm{A} 2$ resulting from an increase in the $\mathrm{OH}$ feature can be observed. Channel A3 does not show any significant changes.

Figure 10 shows the effect of additional water contamination on a sample artificially aged for 9 days, also compared to the signal in fresh oil. Here, A1 shows a large difference between fresh and aged samples, but shows very little change with increasing water content. Channel A2 is only marginally affected and A3 is totally unaffected by the artificial aging, but both reflect the water contamination as expected from the reference spectra (cf. Fig. 5). Therefore, water content and oxidation can be independently determined well for the synthetic motor oil and presumably also for the 


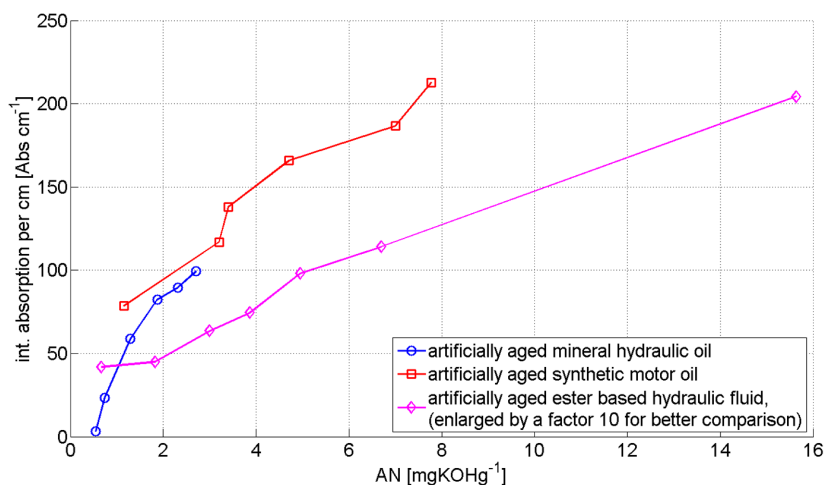

Figure 8. FTIR absorption integrated over the oxidation band plotted vs. acid number (AN) as determined by ASTM D974; evaluated spectral regions are $3333 \mathrm{~cm}^{-1}$ with FHWM $52 \mathrm{~cm}^{-1}$ for the artificially aged ester-based hydraulic fluid (corresponding to filter B1) and $1722 \mathrm{~cm}^{-1}$ with FWHM $151 \mathrm{~cm}^{-1}$, corresponding to filter A1, for the other artificially aged samples (synthetic motor oil, mineral hydraulic oil).

mineral hydraulic oil with the multiple measurement channels. In fact, the third channel could be tailored to indicate another degradation feature, e.g., to reflect the concentration of an additive.

For the artificially aged native ester, increased oxidation can be observed using measurement channels B1 and B2, both of which show a nearly linear decrease in the signal intensity with the duration of the artificial aging after normalization and weighting with the reference channel, Fig. 11. A slight decrease in the reference signal BR can also be observed, while channel B3 does not show a clear trend. Additional water contamination would thus be difficult to differentiate from the effect of oxidation due to the overlap of the spectral features. A correction was suggested by Sumit et al. (2010) using a differential algorithm. Analyzing the spectra of different ester-based hydraulic fluids, e.g., native hydraulic fluids, phosphor acid esters, etc., shows that usable wavelengths can be found (Bley, 2013). However, an adaption of the measurement channels, i.e., the filter wavelengths and possibly also the number of channels, for each fluid is necessary to obtain optimal results.

\subsection{Influence of temperature variations}

For monitoring of the oil degradation during normal operation of a machine the influence of varying ambient and, more importantly, oil temperatures has to be taken into account. Figure 12 (top) shows the reference spectra of synthetic motor oil artificially aged for 9 days and contaminated with 0.4 wt. $\%$ water measured with the FTIR spectrometer at different temperatures. Due to the temperature increase the density of the oil changes. According to the Lambert-Beer law the transmission depends on the concentration of radiationabsorbing molecules that decreases with decreasing density

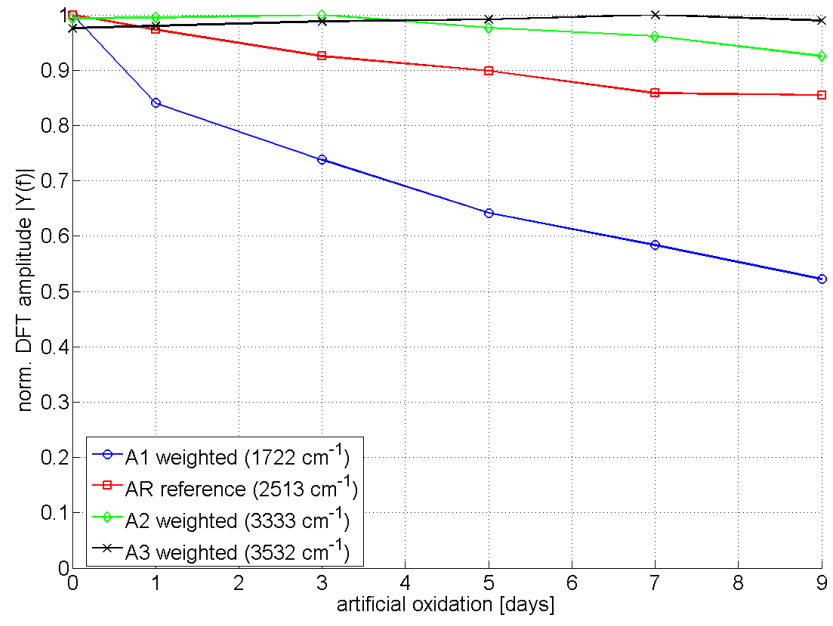

Figure 9. Measurement results for synthetic motor oil artificially aged at $170^{\circ} \mathrm{C}$ with $50 \mathrm{~cm}^{3} \mathrm{~min}^{-1}$ air flow over 9 days, measured with a detector in mineral oil configuration (reference $A R$ ).

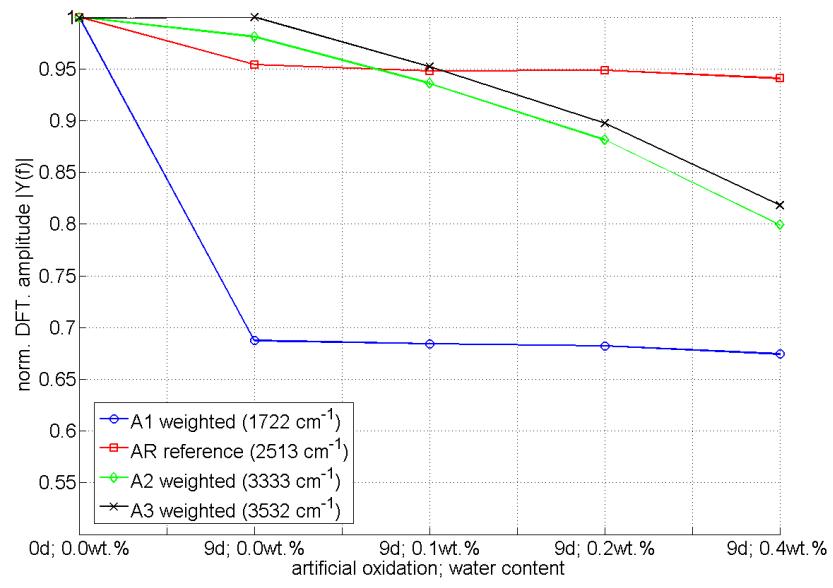

Figure 10. Comparison of aged synthetic motor oil (9 days) with water contaminations of $0,0.1,0.2,0.4 \mathrm{wt} . \%$, respectively, measured with a detector in mineral oil configuration (reference AR).

of the fluid. At the same time, the extinction of the different molecules also changes with temperature as well as the absorption path length due to thermal expansion. Thus, the absorption spectrum will show complex changes when the oil temperature changes. The change of the absorption, $\Delta E(\lambda)$, is shown in Fig. 12 (bottom) for IR spectra measured at a temperature of $40.8,50.8$ and $57.9^{\circ} \mathrm{C}$, respectively, relative to the spectrum at $30.5^{\circ} \mathrm{C}$.

$\Delta E(\lambda)=E(\lambda, T)-E\left(\lambda, 30.5^{\circ} \mathrm{C}\right)$

$E(\lambda, T)$ absorption at temperature $T, \lambda$ wavelength.

Changes in the spectrum caused only by the temperature can be observed. It is interesting to note that some spectral regions show increasing absorption with the temperature, e.g., below 1600 and above $3600 \mathrm{~cm}^{-1}$, while others 


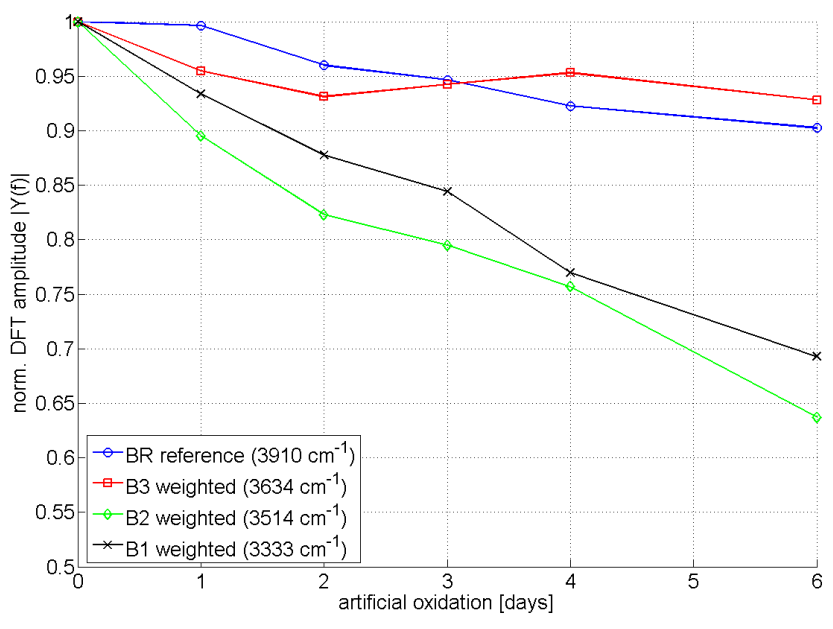

Figure 11. Measurement results for ester-based hydraulic fluid artificially aged at $130{ }^{\circ} \mathrm{C}$ with $50 \mathrm{~cm}^{3} \mathrm{~min}^{-1}$ air flow over 6 days, measured with a detector in ester configuration (reference BR).
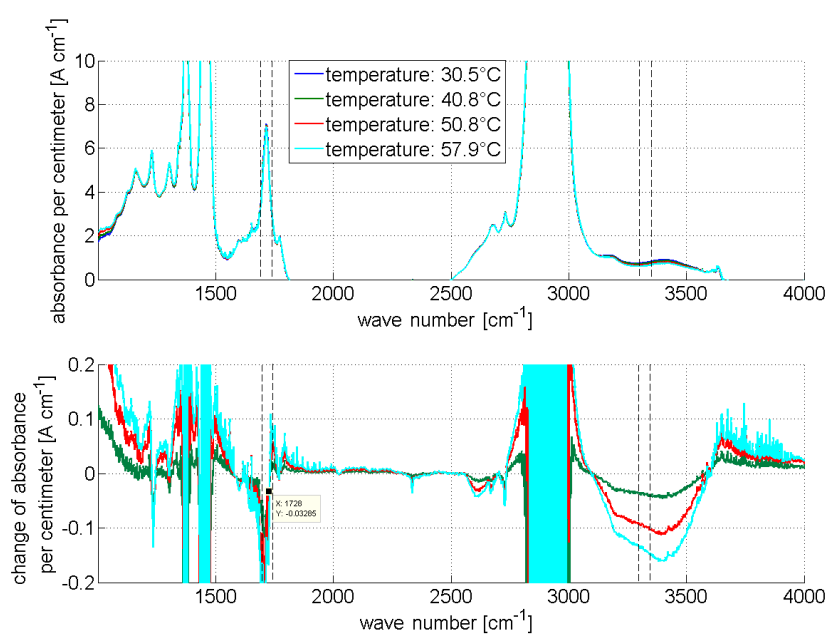

Figure 12. Temperature dependence of the FTIR spectra. Top: Transmission spectra for synthetic motor oil (artificially aged at $170^{\circ} \mathrm{C}$ with $50 \mathrm{~cm}^{3} \mathrm{~min}^{-1}$ air flow over 9 days with $0.4 \mathrm{wt} . \%$ water contamination added after aging) at $30.5,40.8,50.8$ and $57.9^{\circ} \mathrm{C}$. Bottom: Deviation of the transmission spectra at elevated temperatures relative to the transmission at $30.5^{\circ} \mathrm{C}$; areas for calculating the mean values around 1722 and $3333 \mathrm{~cm}^{-1}$ shown in Fig. 13 are marked.

show decreasing absorption, especially the water feature in the range from 3000 to $3600 \mathrm{~cm}^{-1}$. Figure 13 shows the influence of the temperature at $1722 \mathrm{~cm}^{-1}$ (no IR absorption by water molecules) and $3333 \mathrm{~cm}^{-1}$ (IR absorption by water molecules) for different water contaminations. For these calculations a rectangular filter with a filter width of $52 \mathrm{~cm}^{-1}$ was used. As expected, without water $\left(0 \mathrm{wt} . \% \mathrm{H}_{2} \mathrm{O}\right)$ only a minimal change in the spectrum is observed at both wave numbers. This observed change is caused by the density decrease in the absorbing molecules with increasing
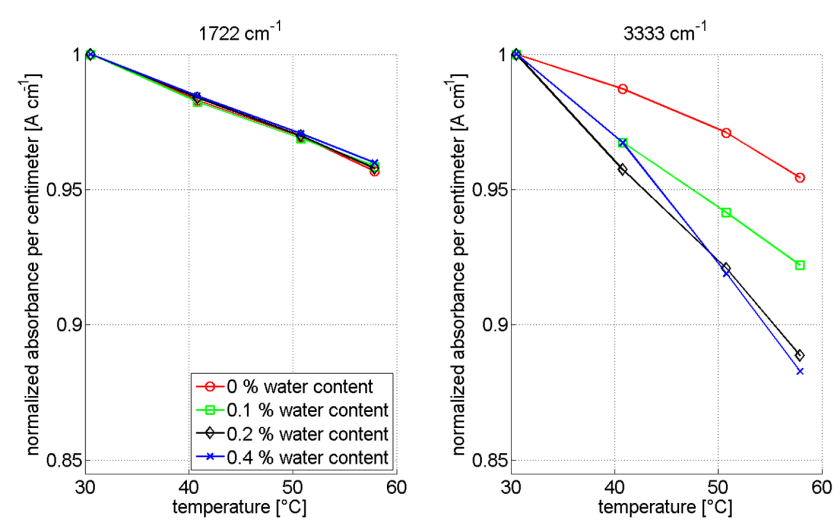

Figure 13. Change in absorbance at 1722 and $3333 \mathrm{~cm}^{-1}$ for aged synthetic motor oil with increasing water content $(0,0.1,0.2$, $0.4 \mathrm{wt} . \%$, respectively) and increasing temperature.

temperature. However, with increasing water content the change in absorption caused by the temperature increases in the IR region around $3333 \mathrm{~cm}^{-1}$. Thus, the temperature has to be measured and taken into account to achieve a good resolution as the influence of changing temperature is on the same order as the effect of water contamination. For practical applications a calibration is required at different temperatures in order to be able to determine the water content correctly under varying operating conditions.

\section{Conclusion and outlook}

Hydrocarbon-based oils, i.e., a synthetic motor oil and a mineral hydraulic oil, as well as an ester-based hydraulic fluid, were analyzed using FTIR spectroscopy to identify the relevant spectral features caused by oxidation and water contamination. In addition, viscosity and acid number were determined using standard laboratory techniques. The FTIR analysis showed that for hydrocarbon-based oils the $\mathrm{C}=\mathrm{O}$ oxidation feature around $1700 \mathrm{~cm}^{-1}$ can be used to evaluate the degree of oxidative degradation. However, the specific composition of the oil has to be taken into account, as additives can already lead to an increased absorption in this region even for fresh oil. For ester-based hydraulic fluids, on the other hand, this feature cannot be used as it already shows total extinction due to the base molecules. Alternatively, the $\mathrm{OH}$ feature can be used to evaluate the degree of oxidation. However, this shows a strong overlap with the effect of water contamination, thus requiring careful selection of the spectral filters and advanced signal analysis to allow independent determination of the oxidative degradation as well as the water content.

A miniaturized multi-channel IR sensor system was presented that is based on a Si flow cell, a micromachined IR source and four thermopiles with specific filters adapted to the application requirements. Two alternatives were presented, one suitable for hydrocarbon-based oils, the other for 
ester-based hydraulic fluids. The sensor system is able to differentiate between increasing oxidation and increasing water contamination for synthetic motor oil and, due to the similarity of the base spectra, also for mineral hydraulic oil. The sensor system is also able to determine the oxidation status of ester-based hydraulic fluids; however, interference caused by water contamination requires advanced signal processing. The sensor system has to be equipped with an oil temperature sensor to compensate temperature dependent changes of the IR transmission spectrum and also requires a comprehensive calibration at different temperatures. On the other hand, the change of the recorded spectral information with temperature can be used to obtain additional information about the oil degradation or the concentration of water contamination.

This study was based on only one aging process, i.e., oxidative aging at elevated temperatures, and one contamination, i.e., with water. Other degradation processes and contaminations need to be studied to ensure that the approach will allow reliable results under various operating conditions. Future experiments will, for example, address the increase in nitric acid components caused by the blow-by effect in combustion engines. A specific IR filter will be implemented in the system for these compounds and controlled aging will be realized with an experimental set-up bubbling $\mathrm{NO}$ in $\mathrm{N}_{2}$ through the oil at elevated temperatures, similar to the analysis of oxidative aging reported here. A combination of different well-controlled processes should also be performed to achieve degradation similar to that observed under normal operating conditions.

Acknowledgements. This work was part of the NaMiFlu project and the FluidSens project and was supported by the German Ministry for Education and Research (BMBF), the federal state of Saarland and the European Fund for Regional Development (EFRE).

Edited by: B. Jakoby

Reviewed by: two anonymous referees

\section{References}

Agoston, A., Ötsch, C., Zhuravleva, J., and Jakoby, B.: An IRAbsorption Sensor System for the Determination of Engine Oil Deterioration, Proceedings of IEEE Sensors Conference, 463466, doi:10.1109/ICSENS.2004.1426200, 2004

Agoston, A., Schneidhofer, C., Dörr, N., and Jakoby, B.: A concept of an infrared sensor system for oil condition monitoring, e \& i Elektrotechnik und Informationstechnik, 125/3, 71-75, doi:10.1007/s00502-008-0506-3, 2008.

ASTM International: Standard Practice for Condition Monitoring of Used Lubricants by Trend Analysis Using Fourier Transform Infrared (FT-IR) Spectrometry, ASTM International, E2412-04, 2007.

ASTM International: Standard Specification for Reagent Water, ASTM International, D1193-06, 2011a.
ASTM International: Standard Test Method for Acid and Base Number by Color-Indicator Titration, ASTM International, D974-11, 2011b.

Bartz, W. J.: Biologisch schnell abbaubare Schmierstoffe und Arbeitsflüssigkeiten (Biologically rapid-degradable lubricants and working fluids), Expert Verlag, 43-44, ISBN 978-3-8169-08104, 1993.

Bley, T.: Integriertes Multisensorsystem zur Zustandsüberwachung von Schmierflüssigkeiten (Integrated Multisensor-System for Condition Monitoring of Lubricating Fluids), Dissertation, Saarland University, Lab for Measurement Technology, Shaker, Aachen, ISBN 978-3-8440-2198-1, 2013.

Bley, T. and Schütze, A.: A Multichannel IR Sensor System for Condition Monitoring of Technical Fluids, Proceedings IRS ${ }^{2}$ 2011 - 12th International Conference on Infrared Sensors and Systems, Nuremberg, 94-99, doi:10.5162/irs11/i4.3, 2011.

Bley, T., Pignanelli, E., and Schütze, A.: Multichannel IR Sensor System for Determination of Oil Degradation, Proc. IMCS 2012: The 14th International Meeting on Chemical Sensors, Nuremberg, Germany, 20-23 May, 2012a.

Bley, T., Pignanelli, E., Fischer, M., Günschmann, S., Müller, J., and Schütze, A.: IR-Optical Oil Quality Sensor System for High Pressure Applications, in: Mechatronics 2012 - The 13th Mechatronics Forum International Conference, Linz, Austria, 17-19 September 2012, edited by: Scheidl, R. and Jacoby, B., Proceedings Vol. 2/3, 351-358, 2012b.

Bley, T., Pignanelli, E., and Schütze, A.: COPS - Combined oil quality and Particle measurement System, ICST2012, Sixth International Conference on Sensing Technology, Kolkata, India, 18-21 December, 2012c.

Booser, E. R.: Handbook of Lubrication and Tribology, Vol. III CRC Press, 23-24, ISBN 978-1-4200-5045-5, 1994.

Burns, D. A. and Ciurczak, E. W.: Handbook of Near-Infrared Analysis, CRC Press, ISBN 978-1-4200-0737-4, 2008.

Duchowsky, J. K. and Mannebach, H.: A Novel Approach to Predictive Maintenance: A Portable, Multi-Component MEMS Sensor for On-Line Monitoring of Fluid Condition in Hydraulic and Lubricating Systems, Tribol. T., 49, 545-553, doi:10.1080/10402000600885183, 2006.

Endisch, P. and Koch, A.: In-situ-Infrarotsensor zur Ölzustandsanalyse (In-situ infrared sensor for oil condition monitoring), XXI, Messtechnisches Symposium des AHMT, Paderborn, 2022 September 2007, Shaker Verlag, ISBN 978-3-8322-6539-7, 190-204, 2007.

Günschmann, S., Fischer, M., Bley, T., Käpplinger, I., Brode, W., Mannebach, H., Müller, J.: Fabrication of a Si-measurement cuvette using a new multifunctional bonding method, CICMT 2012 Ceramic Interconnect \& Ceramic Microsystems Technologies, Erfurt, 2012.

Günschmann, S., Mannebach, H., Steffensky, J., Fischer, M., and Müller, J.: Herstellung einer Messküvette als Teil eines Messsensors für Echtzeit-Ölqualitätsmessungen (Fabrication of a measurement cuvette as part of a sensor for the realtimeoilquality-measurement), MST Congress, Aachen, ISBN 978-38007-3555-6, 2013.

Honary, L. and Richter, E.: Biobased Lubricants and Greases: Technology and Products, John Wiley and Sohns, 65-67, ISBN 978 0-470-74158-0, 2011. 
Intex Inc.: INTX17-0900, available at: www.intexworld.com, last access: 26 June 2013.

Kudlaty, K., Purde, A., and Koch, A. W.: Development of an Infrared Sensor for On-line Analysis of Lubricant Deterioration; Proc. of IEEE Sensors 2003 Vol. 2, 903-908, Toronto, doi:10.1109/ICSENS.2003.1279074, 2003.

Micro-Hybrid Electronic GmbH: Four Channel Thermopile Detector, available at: www.micro-hybrid.de, last access: 26 June 2013.

Mortier, R. M., Fox, M. F., and Orszulik, S. T.: Chemistry and Technology of Lubricants, Springer, 107-115, ISBN 978-1-40208662-5, 2010.

Möller, U. J. and Nassar, J.: Schmierstoffe im Betrieb (Lubricating fluids in practical application), Springer, 662-687, ISBN 978-3642-56379-9, 2002.

OelCheck: Limit values for gas engine oils, available at: http:// www.oelcheck.de/en/home.html (last access: 3 July 2013), 2013.

Pawlak, Z.: Tribochemistry of Lubricating Oils, Elsevier, ISBN 978-0-444-51296-3, 2003.

Pretsch, E., Bühlmann, P., and Bardetscher, M.: Structure Determination of Organic Compounds, Springer, 287-288, ISBN 978-3540-93810-1, 2009.

Schneidhofer, C. and Dörr, N.: Online-Ölzustandsüberwachung mit chemischen Korrosionssensoren (Online oil condition monitoring with chemical corrosion sensors), e \& i Elektrotechnik \& Informationstechnik, 126/1-2, 31-36, doi:10.1007/s00502-0090606-8, 2009.
Sumit, P., Legner, W., Krenkow, A., Müller, G., Lemettais, T., Pradat, F., and Hertens, D.: Chemical Contamination Sensor for Phosphate Ester Hydraulic Fluids, Intern, J. Aerospace Eng., 2010, 156281, doi:10.1155/2010/156281, 2010.

Totten, G. E., Westbrook, S. R., and Shah, R. J.: Fuels and Lubricants Handbook, ASTM International, 787-791, ISBN 9780-8031-2096-9, 2003.

Wang, S. S.: Road tests of oil condition sensor and sensing technique, Sensors und Actuators, B73, 106-111, doi:10.1016/S0925-4005(00)00660-2, 2001.

Wiesent, B. R., Dorigo, D. G., and Koch, A. W.: Limits of IRspectrometers based on linear variable filters and detector arrays, Proc. SPIE 7767, Instrumentation, Metrology, and Standards for Nanomanufacturing IV, 77670L (24 August, 2010); doi:10.1117/12.860532, 2010.

Wiesent, B. R., Dorigo, D. D., and Koch, A. W.: Suitability of tunable Fabry-Perot spectrometers for condition monitoring purposes of gear oils in offshore wind turbines, Proceedings IRS ${ }^{2}$ 2011 - 12th International Conference on Infrared Sensors and Systems, Nuremberg, 82-87, doi:10.5162/irs11/i4.2, 2011. 